The effects of perceived usefulness, confirmation and satisfaction on continuance intention in using massive open online course (MOOC)

\author{
Aisha Aminu Daneji \\ Ahmad Fauzi Mohd Ayub \\ Mas Nida Md. Khambari \\ University Putra Malaysia, Malaysia
}

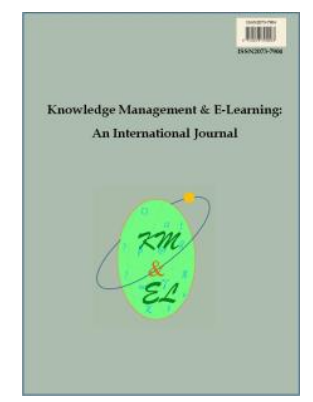

Knowledge Management \& E-Learning: An International Journal (KM\&EL) ISSN 2073-7904

Recommended citation:

Daneji, A. A., Ayub, A. F. M., \& Khambari, M. N. M. (2019). The effects of perceived usefulness, confirmation and satisfaction on continuance intention in using massive open online course (MOOC). Knowledge Management \& E-Learning, 11(2), 201-214. https://doi.org/10.34105/j.kmel.2019.11.010 


\title{
The effects of perceived usefulness, confirmation and satisfaction on continuance intention in using massive open online course (MOOC)
}

\author{
Aisha Aminu Daneji* \\ Faculty of Educational Studies \\ University Putra Malaysia, Malaysia \\ E-mail: aishadaneji@gmail.com
}

\begin{abstract}
Ahmad Fauzi Mohd Ayub
Faculty of Educational Studies Institute for Mathematical Research University Putra Malaysia, Malaysia

E-mail: afmy@upm.edu.my
\end{abstract}

\section{Mas Nida Md. Khambari}

Faculty of Educational Studies University Putra Malaysia, Malaysia

E-mail: khamasnida@upm.edu.my

*Corresponding author

\begin{abstract}
Massive Open Online Course (MOOC) has been playing an important role in the latest e-learning initiative and has obtained a widespread popularity in many universities. However, the low course completion rates of students have become an outstanding issue that should not be neglected. Based on the Expectation-Confirmation Model (ECM), this study examines the effects of students' perceived usefulness, confirmation and satisfaction on MOOC continuance intention. Structural Equation Modeling (SEM) was used to validate the proposed model and hypotheses. Participants were 368 undergraduate students enrolled in a MOOC platform. The study's result revealed that confirmation has significant effects on students' perceived usefulness and satisfaction. Perceived usefulness and satisfaction have significant effects on students' continuance intention while perceived usefulness has no significant effects on students' satisfaction. This study will help to outspread our understanding of what influence students to continue using MOOC.
\end{abstract}

Keywords: Massive open online course; Expectation-confirmation model; Continuance intention; Structural equation modeling; Undergraduate students

Biographical notes: Aisha Aminu Daneji has completed her Master of Science in Educational Technology at Faculty of Educational Studies, Universiti Putra Malaysia. She is currently doing her doctoral degree in the same field. Her research interests include e-learning, and technology-enhanced learning.

Dr. Ahmad Fauzi Mohd Ayub is an Associate Professor in the Faculty of 
Educational Studies at Universiti Putra Malaysia. His field of research is related to information and communication technology in education, mobile learning and multimedia education. He also assists students to develop multimedia tools for educational use. Besides that, Dr. Ahmad Fauzi also teach courses at postgraduate level which includes Computer in Teaching and Learning, Multimedia and Communication Technology covering both instructional, as well as educational statistics courses. He has written papers on the use of learning management systems, integration of computer software in teaching and learning.

Dr. Mas Nida Md. Khambari is a senior lecturer at the Department of Foundations of Education, Faculty of Educational Studies. Her research interests include the use and impact of technology specifically interactive whiteboards and laptops in education, the Cultural Historical Activity Theory, and emerging technology trends in education. She has publications in the area of Educational Communications and Technology.

\section{Introduction}

Massive Open Online Courses (MOOCs) are lessons delivered in an online environment whereby, there is an unlimited participation (Marques, 2013; Alraimi, Zo, \& Ciganek, 2015). As the use of the internet is now a regular means used by students to search for information anytime and anywhere (Ifeanyi \& Chukwuere, 2018). MOOC are free and open to any individual who wants to learn online irrespective of his/her place or education level (Bederson, Russell, \& Klemmer, 2015). This may be the reason why MOOCs have been undergoing a rapid development in recent years (Jordan, 2014; Konstan et al., 2015). Instructors from everywhere in the world can plan and create materials on learning points and put them online (Christensen et al., 2013).

Although MOOC have become very popular and used all over the world, the main issue that cannot be overlooked is the low course completion rate of students (Siemens, 2013; Ouyang et al., 2017). As it is reported in many studies, no more than 10 percent of the registered students can finish a course on MOOCs (Breslow et al., 2013; Catropa, 2013; Ho et al., 2014; Jordan, 2014). Meanwhile, there is high enrollment but only a few learners complete their enrolled courses in MOOC, it is therefore important to study the factors that influence students to continue using the MOOC platform. Additionally, the review of prior studies revealed that only a few studies examined the MOOC continuance intention more specifically in the context of Malaysia.

In the previous years, researchers have successfully applied ECM in various studies to explain continuance intention in several domains. Such as web-based services (Lee \& Kwon, 2011), the use social networking sites (Wang, Xu, \& Chan, 2015) and smartphone banking services (Susanto, Chang, \& Ha, 2016). These studies have proved the validity of the ECM in predicting user's continuance intention. Therefore, it is an appropriate theoretical foundation to explain MOOC continuance intention in this study. As a result, the objective of this study is to empirically test the factors influencing students' continuance intention among Malaysian Higher Education students. 


\section{Literature review}

Malaysia was declared as the first country in the world to implement MOOCs for all public universities and the only country where MOOCs were applied at a national scale through government initiative (Rajendram, 2014). MOOC was initiated by the Ministry of Higher Education, which was incorporated into the Higher Education system. MOOC is currently considered as an essential medium for Malaysian universities to disseminate knowledge conveniently to a larger number of students (Sahimi et al., 2016).

Bhattacherjee (2001) extended Expectation Confirmation Theory (ECT) to build the ECM in order to understand users' intention to continue using an information system (IS). ECT was developed by Oliver (1980) and has been widely used in the marketing field to measure consumer satisfaction and post-purchase behavior. The ECM postulates that satisfaction and perceived usefulness are the fundamental factors that affect continuance intention. Satisfaction is affected by users' perceived usefulness and confirmation; perceived usefulness is affected by users' confirmation (Hossain \& Quaddus, 2012). Bhattacherjee (2001) includes perceived usefulness factor in the ECM model just as in technology acceptance model (TAM). Perceived usefulness is an important factor in TAM-based studies as it is the only factor that has been proved to consistently influence user intention across temporal stages of IS use (Bhattacherjee, 2001). This is why perceived usefulness may be more specific to the context of information systems and expectations-confirmations that may have a broader context.

ECM has been widely applied in various fields, including the information systems and e learning. For example, Stone and Baker-Eveleth (2013) used the ECM to study students' continuance intention with regards to electronic textbooks. The outcome of the study revealed that confirmation have influence on perceived usefulness and satisfaction, while satisfaction and perceived usefulness affect continuance intention to use electronic textbooks. Similarly, Oghuma, Libaque-Saenz, Wong, and Chang (2016) used an amended ECM to examine continuance intention to use mobile instant messaging. In a study of continuance intention to using web service with ECM including intimacy and familiarity, satisfaction was found significant to continuance intention, and both intimacy and familiarity variables were measured to be also important (Lee \& Kwon, 2011). Similarly, Halilovic and Cicic (2013) extended the ECM to examine the antecedents of the information systems user behaviour.

With respect to the MOOC domain, ECM has been applied in various MOOC studies. Such as Xu (2015) who studied MOOCs in China and stated that students' intention with regards to MOOCs were affected by their subjective norms and by the perceived usefulness of the course. Similarly, Alraimi et al. (2015) extended ECM to study continuance intention of MOOC users. Their outcomes showed that perceived reputation and perceived openness were the strongest predictors of MOOC continuance. Lately, Zhou (2017) investigated on factors that influence learners' continuance intention in MOOC for online collaborative learning in Mainland China. The empirical results of the study revealed that the effects of the three ECM factors where significant with learner's continuance intention. Expectation-Confirmation Model (ECM) was found to be a convincing model in explaining users' continuance intention during the past decades (Bhattacherjee, 2001). It reveals the variables that influence the continuance usage intention of individuals in the area of information technologies (Dağhan \& Akkoyunlu, 2016). The variables include perceived usefulness, confirmation, satisfaction and continuance intention. Therefore, ECM is considered as an appropriate theoretical foundation to explain students' MOOC continuance use intention. 


\section{Design research model and hypotheses}

Based on the ECM model, the proposed model of this study includes all the ECM three constructs with regards to continuance intention of MOOC use. Fig. 1 showed the association between the constructs of the study.

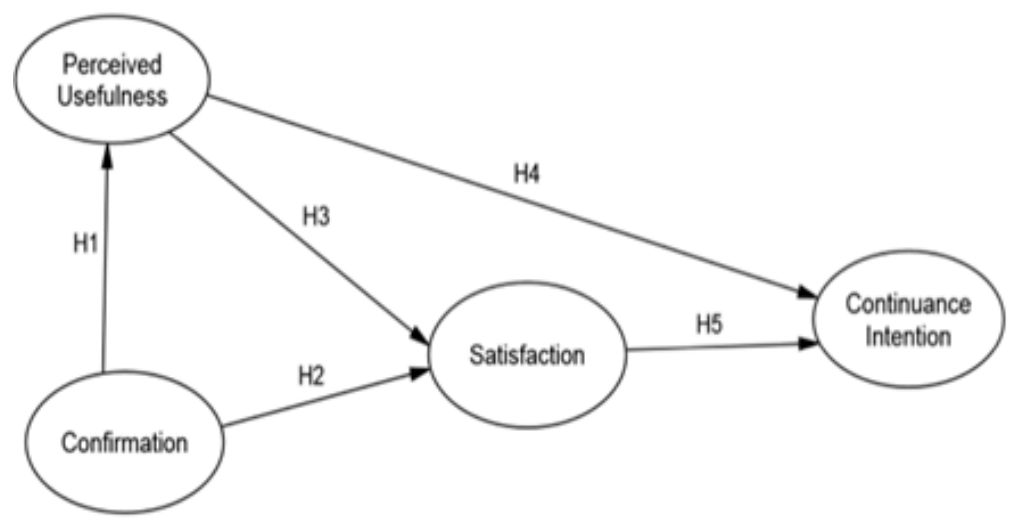

Fig. 1. Proposed research model

\subsection{Confirmation}

Confirmation refers to the opinion of users' congruence between the expectation of IS use and its actual performance (Bhattacherjee, 2001). ECM theorizes that the extent of IS users' confirmation leads to a positive effect on their perceived usefulness and satisfaction of IS (Zhou, 2017). Several studies have revealed a direct positive relationship between users' confirmation on their perceived usefulness and satisfaction (Bhattacherjee, 2001; Oliver, 1980; Venkatesh et al., 2011; Alraimi et al., 2015). If users believe that the IS is very useful and the actual use experience corresponds or goes beyond their initial expectation, the confirmation that exists to leads to user satisfaction (Oghuma et al., 2016; Ouyang et al., 2017). This is because the expected benefits of IS use are realized. Therefore, MOOC users will measure up their actual experience of MOOC with their initial expectation. If their expectation is confirmed, they will be satisfied with the MOOC. Therefore, this study hypothesizes that:

H1: Confirmation has a significant influence on perceived usefulness toward MOOC

H2: Confirmation has a significant influence on satisfaction toward MOOC

\subsection{Perceived usefulness}

Perceived Usefulness is defined as "the degree to which a person believes that using a particular system will increase his or her job performance" (Davis, 1989). Perceived usefulness has been found to be a strong and direct determinant of continuance usage intentions in previous studies (Mouakket, 2015; Wu \& Chen, 2017). It also has a positive influence on users' satisfaction (Bhattacherjee, 2001; Lin \& Lu, 2011). Such association is found in different studies like e-learning systems (Ho, 2010; Almahamid \& Rub, 2011), Electronic textbook (Stone \& Baker-Evelet, 2013), Mobile banking (Yuan, Liu, Yao, \& Liu, 2016) and Mobile commerce (Luqman, Razak, Ismail, \& Alwi, 2016). This implies that, if users believe that using MOOC is very useful to them, they will be more 
satisfied with it and might choose to continue using the MOOC. This study hypothesizes that:

H3: Perceived usefulness has significant influence on satisfaction toward MOOC

H4: Perceived usefulness has significant influence on MOOC continuance Intention

\subsection{Satisfaction}

Satisfaction is one of the significant concepts in ECM. It is defined as the response of users after using an IS (Ouyang et al., 2017). With regards to the ECM, users' continuance intention of IS use is affected by their satisfaction with previous experience and perceived usefulness of IS (Bhattacherjee, 2001). The relationship between users' satisfaction and their continuance intention of a particular IS has been confirmed in previous studies (Thong, Hong, \& Tam, 2006; Liao, Palvia, \& Chen, 2009; Lee, 2010; Alraimi et al., 2015). When users are satisfied with MOOC, there is a likelihood that their intention would be to continue using the MOOC. This study hypothesizes that:

H5: Satisfaction has a significant influence on MOOC continuance Intention

\subsection{Continuance intention}

The continuance intention is the target of the ECM model. It is defined as the intention to continue using an information system (Bhattacherjee, 2001). The proposed ECM was based on the concept that continuance usage intention of a system will be influenced by system usage satisfaction and perceived usefulness (Bhattacherjee, 2001). A report by Basak and Calisir (2015) stated that when an individual start using an information system, psychological motivations can occur which may have an effect on the individuals' continuance decision. As such, an individual would probably have the intention to continue using MOOC if such usage is appreciated. Continuance intention is the dependent variable of the current study as shown in Fig. 1.

\section{Research method}

\subsection{Participants}

The target population of this research includes the undergraduate students from the Malaysian public university. Data were gathered from 368 undergraduate students who registered for a course during 2016/2017 sessions through a period of one month. The demographic profile of the respondents is displayed in Table 1. There were $244(63.3 \%)$ female and $124(33.7 \%)$ male included in this study. In terms of respondents' age, majority of them $(71.7 \%)$ were between 18 to 20 years old, 97 were between 21 to 23 years old and only seven $(1.9 \%)$ of them were above the age of 24 . The racial distribution was $68.6 \%$ Malay, $13.8 \%$ Chinese, closely followed by $11.4 \%$ Indian and $6.3 \%$ of others.

\subsection{Measuring instrument}

An online questionnaire survey was administered to collect the data from students through the putraMOOC portal by pasting the URL on the portal for students to click on the link and respond to the questions. All measurement items of the questionnaire were 
adapted from the previous literature. The questionnaire was adapted from different authors in English Language. It was then reviewed and translated into Malay Language. As the majority of the students in public school were Malay and they may prefer to read the questionnaire in Malay Language. A pilot test was conducted prior to the actual study to refine the instruments. The items for continuance intention and confirmation were adapted from Bhattacherjee (2001). Satisfaction items were adapted from Hsu, Chang, and Lin (2013), while the items for perceived usefulness came from Davis (1989). The questionnaire consisted of two parts. The first part (A) consists of three questions with regards to the background information of the respondents. Such as the gender, age and race. The second part (B) consisted of 14 questions to measure the five constructs of the study. All items in the second part were measured using a 5-point Likert scale, labeled as 1 (strongly disagree), 2 (disagree), 3 (moderately agree), 4 (agree) and 5 (strongly agree). Table 2 displayed the items used in the study and their sources.

\section{Table 1}

Demographic profile of respondents

\begin{tabular}{cccc}
\hline Variable & Category & Frequency & Percentage \% \\
\hline Gender & Male & 124 & 33.7 \\
& Female & 244 & 63.3 \\
Age & $18-20$ & 264 & 71.7 \\
& $21-23$ & 97 & 26.4 \\
\multirow{2}{*}{ Race } & 24 Above & 7 & 1.9 \\
& Malay & 252 & 68.5 \\
& Chinese & 51 & 13.8 \\
& Indian & 42 & 11.4 \\
& Others & 23 & 6.3 \\
\hline
\end{tabular}

Table 2

Survey items

\begin{tabular}{llc}
\hline Code & Item & Source \\
\hline PU1 & Using putraMOOC for my learning enables me to accomplish academic task more quickly. & Davis (1989) \\
PU2 & Using putraMOOC improves my academic performance. & Davis (1989) \\
PU3 & PutraMOOC increases my efficiency in learning. & Davis (1989) \\
PU4 & I find putraMOOC useful for my learning online. & Davis (1989) \\
CONF1 & My experience with using putraMOOC was better than I expected. & Bhattacherjee (2001) \\
CONF2 & The service level provided by putraMOOC was better than I expected. & Bhattacherjee (2001) \\
CONF3 & Most of my expectations from using putraMOOC were confirmed. & Hsu et al., (2013) \\
SAT1 & PutraMOOC was well organized. & Hsu et al., (2013) \\
SAT2 & My decision to use putraMOOC was a wise one & Hsu et al., (2013) \\
SAT3 & I think I did the right thing by deciding to use putraMOOC. & Hsu et al., (2013) \\
SAT4 & I feel extremely satisfied about my overall experience of using putraMOOC. & Bhattacherjee (2001) \\
CI1 & I intend to continue using putraMOOC rather than discontinue its use. & Bhattacherjee (2001) \\
CI2 & My intention is to continue using putraMOOC platform than to use any alternative. & Bhattacherjee (2001) \\
CI3 & If I could, I would like to continue my use of putraMOOC. &
\end{tabular}




\subsection{Learning environment}

The target system is the MOOC at Universiti Putra Malaysia (PutraMOOC). PutraMOOC is recent open service to the community and the world at large (i.e. online learning), which was developed by the University Putra Malaysia. It is easily accessible at no expense, interested individuals only need to register online to be enrolled. The instructors of putraMOOC courses were recommended to use the blended learning mode, where $30 \%$ of the course is conducted in MOOC while the remaining part is carried out according to course instructors in their respective universities. Each putraMOOC course lasts for about seven to eight weeks and the platform is easily accessible 24 hours a day. Courses in different areas of knowledge were made available through video lectures, interactive lecture notes, discussion forums, chats, quizzes and forms of assessments. Presently, putraMOOC is offering Islamic Civilization and Asian Civilization (TITAS), Agriculture and Man, Malay Arts, Malaysian Food Heritage, Ethology and Animal Welfare, Halal Food, Islamic Finance and Water Safety courses.

\section{Data analysis and result}

In analyzing the collected data, Structural Equation Modeling (SEM) was used to analyze the relationships defined in the proposed research model. A two-step procedure was then followed as suggested by Anderson and Gerbing (1988). First, the fitness and the construct validity of the proposed measurement model were examined by assessing the reliability, convergent validity, and discriminant validity. The next step done was examining the structural model to test the strength and the relationships hypothesized in the research model followed this. SEM was used in this study because of its ability to assess a series of interrelationships among latent constructs concurrently in a model (Awang, 2015).

\subsection{Assessment of the measurement model}

The reliability of the data was assessed by Cronbach's alpha to measure the internal consistency. The mean, standard deviation and Cronbach's $\alpha$ of each construct are displayed in Table 3 and each of the Cronbach's alpha is above the recommended value 0.7 (Hair, Black, Babin, \& Anderson, 2010). The result indicates that items in this study have a high internal reliability.

Table 3

Construct reliability

\begin{tabular}{lccc}
\hline Construct & Mean & Standard Deviation & Cronbach's Alpha \\
\hline Perceived Usefulness & 3.67 & .780 & 0.916 \\
Confirmation & 3.54 & .723 & 0.858 \\
Satisfaction & 3.60 & .737 & 0.917 \\
Continuance Intention & 3.45 & .806 & 0.907 \\
\hline
\end{tabular}

A set of indicators that gather to measure a single construct is known as convergent validity (Kline, 2015). Fornell and Larcker (1981) recommended that convergent validity is proved when 1$)$ the item factor loadings $(\lambda)$ are significant and above 0.5 (Awang, 2015; Hair et al., 2010), 2) the composite reliability (CR) of each 
construct is greater than 0.7 (Byrne, 2013; Awang, 2015), 3) the average variance extracted (AVE) exceeds 0.5 (Fornell \& Larcker, 1981; Awang, 2015). As presented in Table 4, the entire item factor loading, the composite reliability (CR) of each construct and the average variance extracted (AVE) satisfied the recommended threshold values. This indicates an acceptable convergent validity.

Table 4

Convergent validity

\begin{tabular}{llccc}
\hline Construct & Item Code & Factor Loading & AVE (>.50) & CR (>.70) \\
\hline Perceived Usefulness & PU1 & 0.796 & 0.743 & 0.920 \\
& PU2 & 0.924 & & \\
& PU3 & 0.949 & & \\
Confirmation & PU4 & 0.763 & & \\
& CONF1 & 0.794 & 0.665 & 0.856 \\
& CONF2 & 0.832 & & \\
Satisfaction & CONF3 & 0.829 & & \\
& SAT1 & 0.679 & 0.688 & 0.897 \\
& SAT2 & 0.892 & & \\
Continuance Intention & SAT3 & 0.920 & & \\
& SAT4 & 0.789 & & \\
& CI1 & 0.878 & 0.768 & \\
& CI2 & 0.856 & & \\
\hline
\end{tabular}

Discriminant validity refers to the extent in which a construct is actually different from other constructs (Hair et al., 2010). Discriminant validity will be met if the AVE for two constructs is higher than their squared correlation $\left(\mathrm{r}^{2}\right)$ as suggested by Fornell and Larcker (1981) and Byrne (2013). For the correlation analysis shown in Table 5, the AVE value for the variables is greater than the off diagonal squared correlations (in bold). This signifies that adequate discriminant validity among the variables was achieved.

Table 5

Discriminant validity index of variables in the measurement model

\begin{tabular}{lcccc}
\hline Construct & PU & CONF & SAT & CI \\
\hline PU & $\mathbf{0 . 7 4 3}$ & & & \\
CONF & 0.152 & $\mathbf{0 . 6 6 5}$ & & \\
SAT & 0.144 & 0.221 & $\mathbf{0 . 6 8 8}$ & \\
CI & 0.137 & 0.160 & 0.168 & $\mathbf{0 . 7 6 8}$ \\
\hline
\end{tabular}




\subsection{Assessment of the structural model}

The structural model was tested to assess how well the model represented the data. The following indices were evaluated: the chi-square test statistic, the goodness-of-fit index (GFI), the normed fit index (NFI), the comparative fit index (CFI), Tucker- Lewis Index (TLI), and the root mean square residual (RMSR). The Relative chi-square $=2.702$, GFI $=0.931$, AGFI $=0.900$, CFI $=0.973$, IFI $=0.973$, TLI $=0.966$ and $\mathrm{RMSEA}=0.068$. These results as shown in Fig. 2 indicated that all the indices have met with the recommended values of a fit model (Gefen, Straub, \& Boudreau, 2003; Bentler \& Bonett, 1980). Thus, indicating that the research model provides a good fit to the study's data.

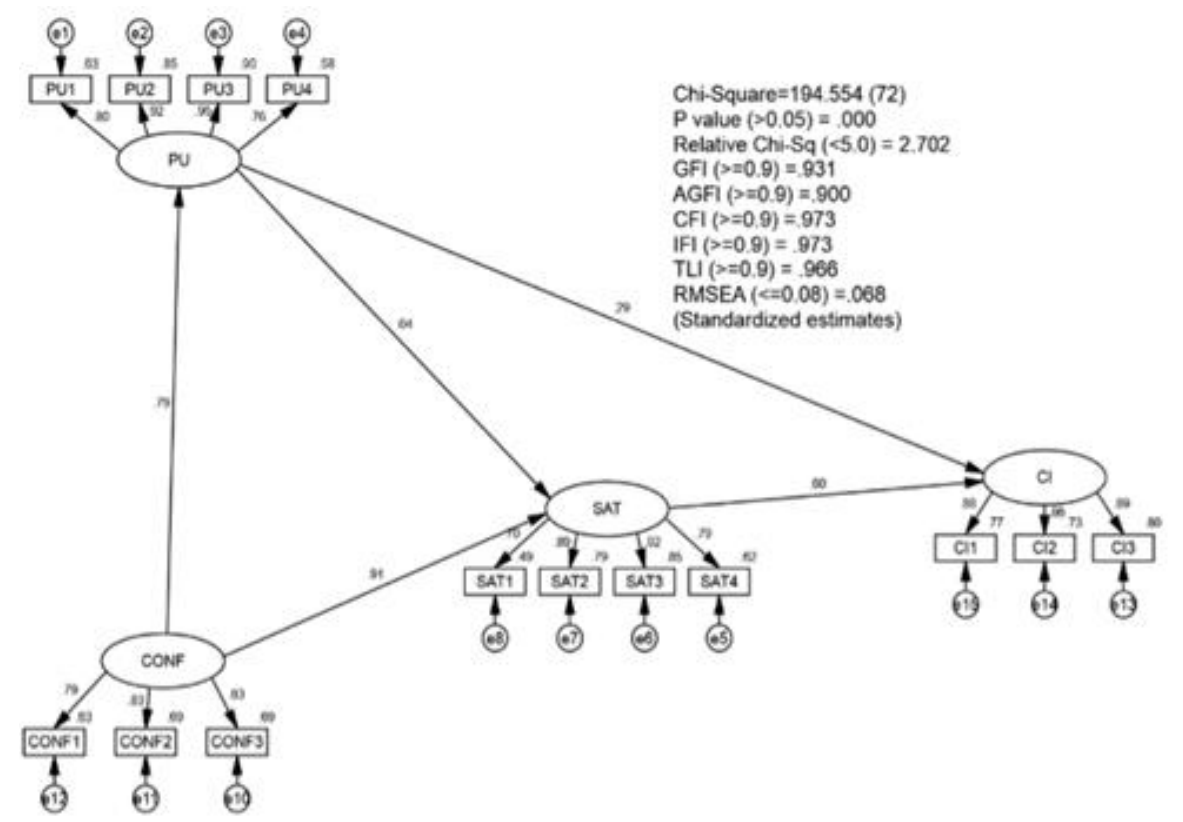

Fig. 2. Structural model

\subsection{Hypotheses testing}

The result of the hypotheses testing as shown in Table 6 shows the five hypothesized relationships between the constructs of the study. The results significantly support all hypotheses except the link between perceived usefulness and satisfaction (H3).

Table 6

Hypotheses testing results

\begin{tabular}{llccl}
\hline & Path & Beta & p-Level & Results \\
\hline H1 & CONF $\rightarrow$ PU & 0.792 & $* * *$ & Supported \\
H2 & CONF $\rightarrow$ SAT & 0.911 & $* * *$ & Supported \\
H3 & PU $\rightarrow$ SAT & 0.037 & 0.560 & Not Supported \\
H4 & PU $\rightarrow$ CI & 0.295 & $* * *$ & Supported \\
H5 & SAT $\rightarrow$ CI & 0.600 & $* * *$ & Supported \\
\hline
\end{tabular}

Note. $*: p<0.1 ; * *: p<0.01 ; * * *: p<0.001$ 
The results revealed that confirmation has a positive influence on perceived usefulness $(\beta=0.792, p=<.001)$ and satisfaction $(\beta=0.911, p=<.001)$ supporting H1 and $\mathrm{H} 2$. Perceived Usefulness was found to have an insignificant association with satisfaction $(\beta=0.037, p>.001)$ and thus $\mathrm{H} 3$ was rejected. Perceived usefulness was seen to have a positive association with continuance intention $(\beta=0.295, \mathrm{p}<.001)$, supporting H4. Satisfaction positively influences continuance intention $(\beta=0.600, p<.001)$ and thus, H5 was supported. The path coefficients were shown in Fig. 2.

\section{Discussion}

The aim of this research was to examine the factors that influence students' intentions to continue using MOOC. The results showed that confirmation significantly influences perceived usefulness and satisfaction. These findings are in accordance with preceding ECM-based studies (Bhattacherjee, 2001; Halilovic \& Cicic, 2013; Oghuma et al., 2016). Confirmation was also found to be the strongest predictor of students' satisfaction than perceived usefulness. This indicates that the accomplishment of students' expectation on the performance of MOOC activities is much more important to their satisfaction which may indirectly have an effect on the continuance usage of MOOC.

The results also revealed that a significant association does not exist between perceived usefulness and satisfaction. This is in line with previous studies that found no significant relationship between perceived usefulness and satisfaction (Alraimi et al., 2015; Chang, Hung, Cheng, \& Wu, 2015). As reported by Olasina (2018), majority students are usually concerned about their individual needs in their approach to using the e-learning system. This suggests that students' perceived usefulness provides limited support in developing their satisfaction towards using MOOC. They also consider their confirmation as more important than the perceived usefulness of MOOC in forming their level of satisfaction. It is observed that satisfaction and perceived usefulness were the significant predictors of MOOC continuance intention. This finding is in agreement with the findings of Barnes and Bohringer (2011), Mouakket (2015) and Wu and Chen (2017). This implies that when students are satisfied and believe that using MOOC can improve their learning performance, they will have a greater intention to continue using MOOC. This study furthermore confirms satisfaction as the most influential factor in predicting students' continuance intention of MOOC use which is consistent with the studies of the IS continuance model (Bhattacherjee, 2001). Impliedly, if the students were satisfied that MOOC is well organized and their decision to use the MOOC was a wise one, they tend to continue using it. Similarly, improving the MOOC design output by considering the learners' point of view, requirements and expectations will give more chance to satisfy large number of learners, in this way giving them view of their learning directions (Cirulli, Elia, \& Solazzo, 2017).

From practitioners' view, this study showed that monitoring and improving students' satisfaction and continuance intention in using MOOC is an important aspect of the MOOC use. So, MOOC providers need to comprehend all the various drivers and possible challenges that are needed to increase the level of satisfaction and continuance use intention among the students so as to improve the value and the effectiveness of the MOOC system. It is obvious that when students believe studying on MOOC platforms will be useful in improving their capability or helpful for them to find new jobs, they will tend to continue using the MOOC system. Therefore, it becomes an important aspect for MOOC suppliers to develop on the quality of the courses, provide new features and ensure the stability of the system. So as to provide a complete online support in the 
overall MOOC design (Cirulli et al., 2017) with the expectation that it will consequently improve students' perceived usefulness and their confirmation in using MOOC.

\section{Conclusion}

The objective of this study was to investigate the factors that influence students' intention to continue using MOOC. A research model based on the expectation-confirmation model (ECM) was proposed and tested with data collected from 368 putraMOOC students. The outcomes of SEM analysis in this study revealed that confirmation has a significant influence on students' perceived usefulness and satisfaction while perceived usefulness has no significant influence on students' satisfaction. The influence of perceived usefulness and satisfaction on students' continuance intention in using MOOC is significant. This indicates that students are willing to continue using MOOC based on the positive significant influence of students' perceived usefulness and satisfaction on continuance intention. The results also showed that expectation exceeds usefulness, being more decisive for satisfaction. These findings statistically support that ECM model successfully establishes the key factors influencing the continuance usage of MOOC.

This study was limited to only the MOOC that was introduced by Universiti Putra Malaysia (putraMOOC), hence the findings of the study may not be generalizable to MOOCs in other Universities. The sample population for the study includes only undergraduates in Malaysian Public Universities who are enrolled in one of the putraMOOC course during their period of study. The current research findings contribute to the existing literature with respect to the ECM model. It also has a value to researchers and practitioners in gaining a better understanding of why users continue to use MOOC.

\section{ORCID}

Aisha Aminu Daneji (D) https://orcid.org/0000-0001-5647-6225

Ahmad Fauzi Mohd Ayub (iD https://orcid.org/0000-0002-4313-2922

Mas Nida Md. Khambari (iD http://orcid.org/0000-0002-7517-9442

\section{References}

Almahamid, S., \& Rub, F. A. (2011). Factors that determine continuance intention to use e-learning system: An empirical investigation. In Proceedings of the International Conference on Telecommunication Technology and Applications (Vol. 5, pp. 242246).

Alraimi, K. M., Zo, H., \& Ciganek, A. P. (2015). Understanding the MOOCs continuance: The role of openness and reputation. Computers \& Education, 80, 28-38.

Anderson, J. C., \& Gerbing, D. W. (1988). Structural equation modeling in practice: A review and recommended two-step approach. Psychological Bulletin, 103(3), 411423.

Awang, Z. (2015). SEM made simple: A gentle approach to learning structural equation modeling. MPWS Rich Publication.

Barnes, S. J., \& Böhringer, M. (2011). Modeling use continuance behavior in microblogging services: The case of Twitter. Journal of Computer Information Systems, 51(4), 1-10. 
Basak, E., \& Calisir, F. (2015). An empirical study on factors affecting continuance intention of using Facebook. Computers in Human Behavior, 48, 181-189.

Bederson, B. B., Russell, D. M., \& Klemmer, S. (2015). Introduction to online learning at scale. ACM Transactions on Computer-Human Interaction (TOCHI), 22: 5.

Bentler, P. M., \& Bonett, D. G. (1980). Significance tests and goodness of fit in the analysis of covariance structures. Psychological Bulletin, 88(3), 588-606.

Bhattacherjee, A. (2001). Understanding information systems continuance: An expectation-confirmation model. MIS Quarterly, 25(3), 351-370.

Breslow, L., Pritchard, D. E., DeBoer, J., Stump, G. S., Ho, A. D., \& Seaton, D. T. (2013). Studying learning in the worldwide classroom: Research into edX's first MOOC. Research \& Practice in Assessment, 8(1), 13-25.

Byrne, B. M. (2013). Structural equation modeling with Mplus: Basic concepts, applications, and programming. New York, NY: Routledge.

Catropa, D. (2013). Big (MOOC) data. Retrieved from https://www.insidehighered.com/blogs/stratedgy/big-mooc-data

Chang, C. C., Hung, S. W., Cheng, M. J., \& Wu, C. Y. (2015). Exploring the intention to continue using social networking sites: The case of Facebook. Technological Forecasting and Social Change, 95, 48-56.

Christensen, G., Steinmetz, A., Alcorn, B., Bennett, A., Woods, D., \& Emanuel, E. J. (2013). The MOOC phenomenon: Who takes massive open online courses and why? Retrieved From http://dx.doi.org/10.2139/ssrn.2350964

Cirulli, F., Elia, G., \& Solazzo, G. (2017). A double-loop evaluation process for MOOC design and its pilot application in the university domain. Knowledge Management \& E-Learning, 9(4), 433-448.

Dağhan, G., \& Akkoyunlu, B. (2016). Modeling the continuance usage intention of online learning environments. Computers in Human Behavior, 60, 198-211.

Davis, F. D. (1989). Perceived usefulness, perceived ease of use, and user acceptance of information technology. MIS Quarterly, 13(3), 319-340.

Fornell, C., \& Larcker, D. F. (1981). Evaluating structural equation models with unobservable variables and measurement error. Journal of Marketing Research, 18(1), 39-50.

Gefen, D., Straub, D., \& Boudreau, M. C. (2000). Structural equation modeling and regression: Guidelines for research practice. Communications of the Association for Information Systems, 4(1): 7.

Hair, J. F., Black, W. C., Babin, B. J., \& Anderson, R. E. (2010). Multivariate data analysis (7th ed.). New Jersey: Prentice-Hall.

Halilovic, S., \& Cicic, M. (2013). Antecedents of information systems user behaviourextended expectation-confirmation model. Behaviour \& Information Technology, 32(4), 359-370.

Ho, C. H. (2010). Continuance intention of e-learning platform: Toward an integrated model. International Journal of Electronic Business Management, 8(3), 206-215.

Ho, A. D., Reich, J., Nesterko, S. O., Seaton, D. T., Mullaney, T., Waldo, J., \& Chuang, I. (2014). HarvardX and MITx: The first year of open online courses, fall 2012-summer 2013. Retrieved

from https://dash.harvard.edu/bitstream/handle/1/11987422/1\%20HarvardX\%20MITx\%20 Report.pdf?sequence $=1$

Hossain, M. A., \& Quaddus, M. (2012). Expectation-confirmation theory in information system research: A review and analysis. In Y. K. Dwivedi, M. R. Wade, \& S. L. Schneberger (Eds.), Information Systems Theory (pp. 441-469). Springer.

Hsu, H. H., Chang, C. C., \& Lin, T. H. (2013). An empirical study of users' continuance intention and word of mouth toward SNA (Social Network App). In Proceedings of the International Conference on Technology Innovation and Industrial Management 
(pp. S6_174-183). ToKnowPress.

Ifeanyi, I. P., \& Chukwuere, J. E. (2018). The impact of using smartphones on the academic performance of undergraduate students. Knowledge Management \& ELearning, 10(3), 290-308.

Jordan, K. (2014). Initial trends in enrolment and completion of massive open online courses. The International Review of Research in Open and Distributed Learning, 15(1), 133-159.

Kline, R. B. (2015). Principles and practice of structural equation modeling (4th ed.). New York, NY: Guilford Publications.

Konstan, J. A., Walker, J. D., Brooks, D. C., Brown, K., \& Ekstrand, M. D. (2015). Teaching recommender systems at large scale: Evaluation and lessons learned from a hybrid MOOC. ACM Transactions on Computer-Human Interaction (TOCHI), 22: 10.

Lee, M. C. (2010). Explaining and predicting users' continuance intention toward elearning: An extension of the expectation-confirmation model. Computers \& Education, 54(2),506-516.

Lee, Y., \& Kwon, O. (2011). Intimacy, familiarity and continuance intention: An extended expectation-confirmation model in web-based services. Electronic Commerce Research and Applications, 10(3), 342-357.

Liao, C., Palvia, P., \& Chen, J. L. (2009). Information technology adoption behaviour life cycle: Toward a technology continuance theory (TCT). International Journal of Information Management, 29(4), 309-320.

Lin, K. Y., \& Lu, H. P. (2011). Why people use social networking sites: An empirical study integrating network externalities and motivation theory. Computers in Human Behavior, 27(3), 1152-1161.

Luqman, A., Razak, R. C., Ismail, M., \& Alwi, M. A. M. (2016). The influence of individual characteristics in predicting mobile commerce usage activities' continuance intention. Journal of Entrepreneurship and Business, 4(2), 54-69.

Marques, J. (2013). A short history of MOOCs and distance learning. MOOC News and Reviews. Retrieved from http://moocnewsandreviews.com/a-short-history-of-moocsand-distance-learning/

Mouakket, S. (2015). Factors influencing continuance intention to use social network sites: The Facebook case. Computers in Human Behavior, 53, 102-110.

Oghuma, A. P., Libaque-Saenz, C. F., Wong, S. F., \& Chang, Y. (2016). An expectationconfirmation model of continuance intention to use mobile instant messaging. Telematics and Informatics, 33(1), 34-47.

Olasina, G. (2018). Factors of best practices of e-learning among undergraduate students. Knowledge Management \& E-Learning, 10(3), 265-289.

Oliver, R. L. (1980). A cognitive model of the antecedents and consequences of satisfaction decisions. Journal of Marketing Research, 17(4), 460-469.

Ouyang, Y., Tang, C., Rong, W., Zhang, L., Yin, C., \& Xiong, Z. (2017, January). Tasktechnology fit aware expectation-confirmation model towards understanding of MOOCs continued usage intention. In Proceedings of the 50th Hawaii International Conference on System Sciences.

Rajendram, R. (2014). Government boost for online learning. The STAR Online. Retrieved from https://www.thestar.com.my/news/education/2014/10/05/govt-boostfor-online-learning/

Sahimi, S. M., Zain, F. M., Alias, A. K., Atan, H., \& Ab Jalil, H. (2016). MOOC at Universiti Sains Malaysia: Factors impacting the teaching and learning outcomes of TITAS course. In J. E. Luaran, J. Sardi, A. Aziz, \& N. A. Alias (Eds.), Envisioning the Future of Online Learning (pp. 183-191). Springer.

Siemens, G. (2013). Massive open online courses: Innovation in education. In R. 
McGreal, W. Kinuthia, \& S. Marshall (Eds.), Open Educational Resources: Innovation, Research and Practice (pp. 5-15). Commonwealth of Learning and Athabasca University, Canada.

Stone, R. W., \& Baker-Eveleth, L. (2013). Students' expectation, confirmation, and continuance intention to use electronic textbooks. Computers in Human Behavior, 29(3), 984-990.

Susanto, A., Chang, Y., \& Ha, Y. (2016). Determinants of continuance intention to use the smartphone banking services: An extension to the expectation-confirmation model. Industrial Management \& Data Systems, 116(3), 508-525.

Thong, J. Y. L., Hong, S. J., \& Tam, K. Y. (2006). The effects of post-adoption beliefs on the expectation-confirmation model for information technology continuance. International Journal of Human-Computer Studies, 64(9), 799-810.

Venkatesh, V., Thong, J. Y. L., Chan, F. K. Y., Hu, P. J. H., \& Brown, S. A. (2011). Extending the two-stage information systems continuance model: Incorporating UTAUT predictors and the role of context. Information Systems Journal, 21(6), 527555.

Wang, D., Xu, L., \& Chan, H. C. (2015). Understanding the continuance use of social network sites: A computer self-efficacy perspective. Behaviour \& Information Technology, 34(2), 204-216.

$\mathrm{Wu}, \mathrm{B} ., \quad \&$ Chen, X. (2017). Continuance intention to use MOOCs: Integrating the technology acceptance model (TAM) and task technology fit (TTF) model. Computers in Human Behavior, 67, 221-232.

$\mathrm{Xu}, \mathrm{F}$. (2015). Research of the MOOC study behavior influencing factors. In Proceedings of the International Conference on Advanced Information and Communication Technology for Education.

Yuan, S., Liu, Y., Yao, R., \& Liu, J. (2016). An investigation of users' continuance intention towards mobile banking in China. Information Development, 32(1), 20-34.

Zhou J. (2017). Exploring the factors affecting learners' continuance intention of MOOCs for online collaborative learning: An extended ECM perspective. Australasian Journal of Educational Technology, 33(5), 123-135. 